Check for updates

Cite this: Chem. Sci., 2019, 10, 7975

๑ All publication charges for this article have been paid for by the Royal Society of Chemistry

\section{Highly efficient electroconversion of carbon dioxide into hydrocarbons by cathodized copper- organic frameworks $\uparrow$}

\author{
Fan Yang, Aling Chen, Pei Lin Deng, Yinzheng Zhou, Zaman Shahid, Hongfang Liu (iD \\ and Bao Yu Xia (D) *
}

Highly selective conversion of carbon dioxide $\left(\mathrm{CO}_{2}\right)$ into valuable hydrocarbons is promising yet challenging in developing effective electrocatalysts. Herein, $\mathrm{Cu}^{\prime \prime} /$ adeninato/carboxylato metal-biomolecule frameworks (Cu"lade-MOFs) are employed for efficient $\mathrm{CO}_{2}$ electro-conversion towards hydrocarbon generation. The cathodized Cu"lade-MOF nanosheets demonstrate excellent catalytic performance for $\mathrm{CO}_{2}$ conversion into valuable hydrocarbons with a total hydrocarbon faradaic efficiency (FE) of over $73 \%$. Ethylene $\left(\mathrm{C}_{2} \mathrm{H}_{4}\right)$ is produced with a maximum $\mathrm{FE}$ of $45 \%$ and a current density of $8.5 \mathrm{~mA} \mathrm{~cm}^{-2}$ at $-1.4 \mathrm{~V}$ vs. RHE, while methane $\left(\mathrm{CH}_{4}\right)$ is produced with a $\mathrm{FE}$ of $50 \%$ and current density of $\sim 15 \mathrm{~mA} \mathrm{~cm}{ }^{-2}$ at -1.6 $\checkmark$ vs. RHE. These investigations reveal that the reconstruction of cathodized $\mathrm{Cu}^{\prime \prime} / \mathrm{ade}-\mathrm{MOFs}$ and the formed $\mathrm{Cu}$ nanoparticles functionalized by nitrogen-containing ligands contribute to the excellent $\mathrm{CO}_{2}$ conversion performance. Furthermore, this work would provide valuable insights and opportunities for the rational design of $\mathrm{Cu}$-based MOF catalysts for highly efficient conversion of $\mathrm{CO}_{2}$ towards hydrocarbon generation.
Received 29th May 2019

Accepted 2nd July 2019

DOI: $10.1039 /$ c9sc02605c

rsc.li/chemical-science ethylene $\left(\mathrm{C}_{2} \mathrm{H}_{4}\right)$ are more desirable for further industrial practices. ${ }^{11,12}$ Copper $(\mathrm{Cu})$ based nanomaterials show the potential capability to generate various hydrocarbons. ${ }^{13-16}$ Nevertheless, these inorganic $\mathrm{Cu}$ compounds suffer from low efficiency and selectivity for $\mathrm{CO}_{2}$ conversion towards hydrocarbon production. ${ }^{17-20}$

Recently, porous metal-organic frameworks (MOFs) constructed from the coordination bonds of organic ligands and metal ions have attracted extensive interest. ${ }^{21}$ The adjustable molecular structures and metal categories make MOFs emerging alternatives for multidisciplinary catalysis applications. $^{22,23}$ Especially, the atomic level periodicity of $\mathrm{Cu}$ complexes allows the design of $\mathrm{Cu}$ active sites for potential $\mathrm{CO}_{2}$ electrolysis. $^{24-26}$ For example, $\mathrm{Cu}$ porphyrin molecules can convert $\mathrm{CO}_{2}$ to $\mathrm{CH}_{4}$ with a faradaic efficiency (FE) of $\sim 30 \%$ at $-0.98 \mathrm{~V} v s$. RHE, ${ }^{23}$ while $\mathrm{Cu}$ phthalocyanine shows an $\mathrm{FE}$ for $\mathrm{CH}_{4}$ of $66 \%$ at $-1.06 \mathrm{~V}$ (vs. RHE) ${ }^{25}$ Nevertheless, crystalline $\mathrm{Cu}-$ MOFs themselves show a limited efficiency for electrochemical conversion of $\mathrm{CO}_{2}$ to $\mathrm{C}_{2}$ products. For example, the $\mathrm{Cu}$ (II) benzene-1,3,5-tricarboxylate (btc) MOF (HKUST-1) facilitates the production of $\mathrm{CH}_{4}$ with a maximum faradaic efficiency of $27 \%$ and a partial current density of $4.4 \mathrm{~mA} \mathrm{~cm}^{-2}$ at $-1.16 \mathrm{~V}$ ( $v s$. RHE), ${ }^{25}$ while the $\mathrm{Cu}_{2}$ (CuTCPP) MOF facilitates the formation of formate and acetate with a total current density of $4.5 \mathrm{~mA} \mathrm{~cm} \mathrm{~cm}^{-2}$ and total faradaic efficiency of $85 \% .^{26}$ Another type of $\mathrm{Cu} \mathrm{MOF}$, named $\left[\mathrm{Cu}_{2}(\text { ade })_{2}\left(\mathrm{CH}_{3} \mathrm{COO}\right)_{2}\right]$, facilitates the formation of a little amount of $\mathrm{CH}_{3} \mathrm{OH}$ with $0.7 \% \mathrm{FE}$ and $\mathrm{C}_{2} \mathrm{H}_{5} \mathrm{OH}$ with $0.5 \%$
Key Laboratory of Material Chemistry for Energy Conversion and Storage (Ministry of Education), Key Laboratory of Material Chemistry and Service Failure, School of Chemistry and Chemical Engineering, Wuhan National Laboratory for Optoelectronics, Huazhong University of Science and Technology (HUST), 1037 Luoyu Road, Wuhan 430074, PR China. E-mail: byxia@hust.edu.cn

$\dagger$ Electronic supplementary information (ESI) available. See DOI: 10.1039/c9sc02605c 
FE for $\mathrm{CO}_{2}$ conversion at $-1.55 \mathrm{~V} v s$. $\mathrm{RHE}^{27}$ Moreover, these Cubased active materials often exhibit structural evolution under the cathodic reductive environment but are rarely reported. ${ }^{25,28}$ Therefore, developing suitable Cu-MOF nanocatalysts and investigating their structural evolution would be significant for further understanding MOF-based catalysts in highly selective $\mathrm{CO}_{2}$ conversion towards valuable hydrocarbon chemical production.

In this work, $\mathrm{Cu}$-ade MOFs are employed to investigate their structure and performance for the selective conversion of $\mathrm{CO}_{2}$. Interestingly, the $\mathrm{Cu}$-ade nanosheets demonstrate an excellent catalytic performance towards hydrocarbon production with a total hydrocarbon faradaic efficiency (FE) of over $73 \%$. Predominantly, ethylene $\left(\mathrm{C}_{2} \mathrm{H}_{4}\right)$ with a maximum $\mathrm{FE}$ of $45 \%$ is mainly produced at $-1.4 \mathrm{~V} v$ s. RHE with a current density of 8.5 $\mathrm{mA} \mathrm{cm}{ }^{-2}$, while methane $\left(\mathrm{CH}_{4}\right)$ is mainly produced at $-1.6 \mathrm{~V} v \mathrm{~s}$. RHE with an FE of $50 \%$ and a current density of $\sim 15 \mathrm{~mA} \mathrm{~cm}^{-2}$. Characterization results and electrochemical analysis reveal the reconstruction of cathodized Cu-MOFs accompanied by the formation of $\mathrm{Cu}$ nanocrystals. Along with the residual ligands, these active $\mathrm{Cu}$ crystals would be responsible for the excellent $\mathrm{CO}_{2}$ conversion towards hydrocarbon production. The contemporary approach towards structural evolution of $\mathrm{Cu}$ MOFs for $\mathrm{CO}_{2}$ conversion to hydrocarbons would provide valuable understanding in developing efficient $\mathrm{Cu}-\mathrm{MOF}$ catalysts for selective $\mathrm{CO}_{2}$ electrolysis and beyond.

The $\mathrm{Cu}$-ade MOF nanosheets are constructed by coordinating $\mathrm{Cu}^{2+}$ ions with adenine and acetic acid (Fig. 1a). ${ }^{29-31}$ The biomolecular adeninato/carboxylato ligands not only scaffold the abundant pores of $\mathrm{Cu}$-ade MOFs but may also contribute protons to enhance the $\mathrm{CO}_{2}$ electroreduction process due to the presence of $\mathrm{N}$-containing functional groups. ${ }^{32-35}$ Three $\mathrm{Cu}$-ade MOFs with different thicknesses, named $\mathrm{Cu}$-ade nanosheets (s$\mathrm{Cu}$-ade), nanoplates ( $\mathrm{p}$-Cu-ade) and nanocuboids (c-Cu-ade), are prepared by tuning the volume ratio of methanol and water (Fig. S1 $\dagger$ ). X-ray powder diffraction (XRD) patterns of MOF products are consistent with metal-adeninate frameworks, which reveals the successful formation of crystalline $\mathrm{Cu}$-ade MOFs (Fig. 1b and S1†). ${ }^{36}$ Scanning electron microscopy (SEM) demonstrates that the $\mathrm{Cu}$-ade MOFs have a width of $\sim 500 \mathrm{~nm}$ and a length of several micrometers (Fig. 1c). Notably, the transparent property suggests the thin nanosheet structure of $\mathrm{Cu}$-ade MOFs. The transmission electron microscopy (TEM) image further confirms the thin two-dimensional structure, and the transparent $\mathrm{Cu}$-ade MOF nanosheet shows a porous structure with a smooth surface (Fig. 1d).

The $\mathrm{CO}_{2}$ electroreduction measurements of $\mathrm{Cu}$-ade MOFs are performed in $\mathrm{CO}_{2}$-saturated $0.1 \mathrm{M} \mathrm{KHCO}_{3}$ electrolyte at the potential ranging from $-1.2 \mathrm{~V}$ to $-1.6 \mathrm{~V} v s$. RHE. Fig. 2a demonstrates the potential-dependent current response in Ar-/ $\mathrm{CO}_{2}$-saturated $\mathrm{KHCO}_{3}$ solution. Compared with the current response in Ar-saturated electrolyte, the significant enhancement of current density in the $\mathrm{CO}_{2}$-saturated electrolyte implies that the $\mathrm{Cu}$-ade $\mathrm{MOF}$ catalysts may have potential catalytic activity for $\mathrm{CO}_{2}$ reduction. The gaseous products are monitored by using two online gas chromatography (GC) systems (Fig. S2 $\dagger$ ), and the liquid products are analyzed using the nuclear magnetic resonance (NMR) technique (Fig. S3†). When (a)
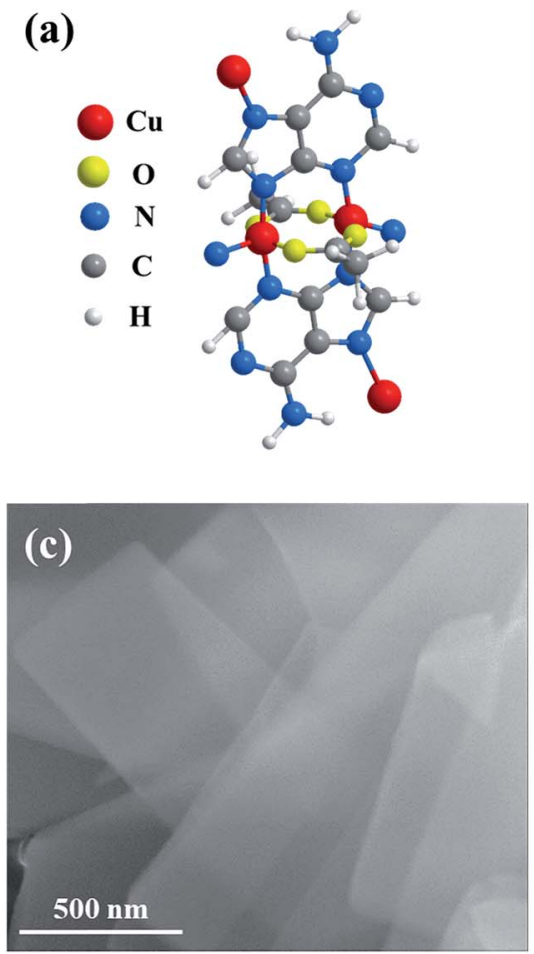
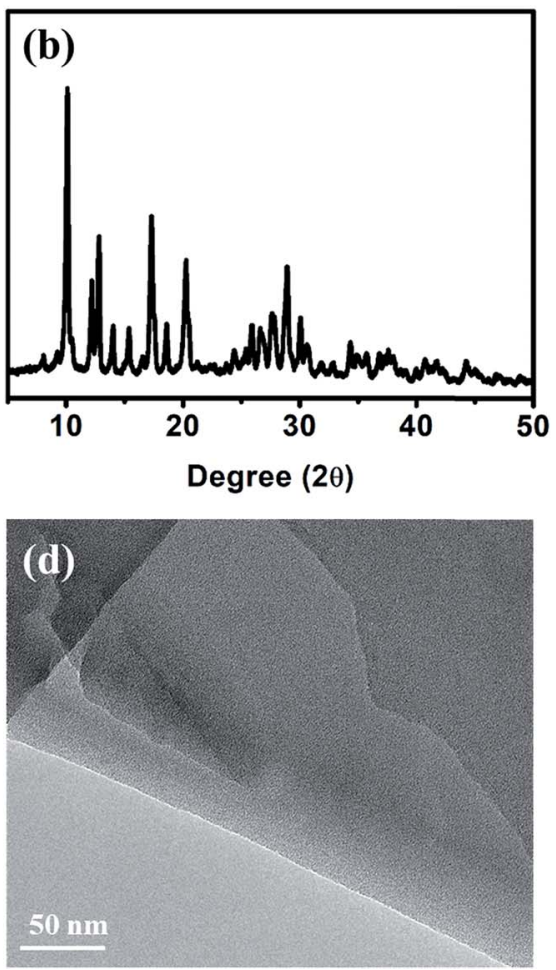

Fig. 1 (a) Molecular structure of the Cu-ade monomer, (b) XRD pattern, (c) SEM image, and (d) TEM image of the s-Cu-ade MOF. 

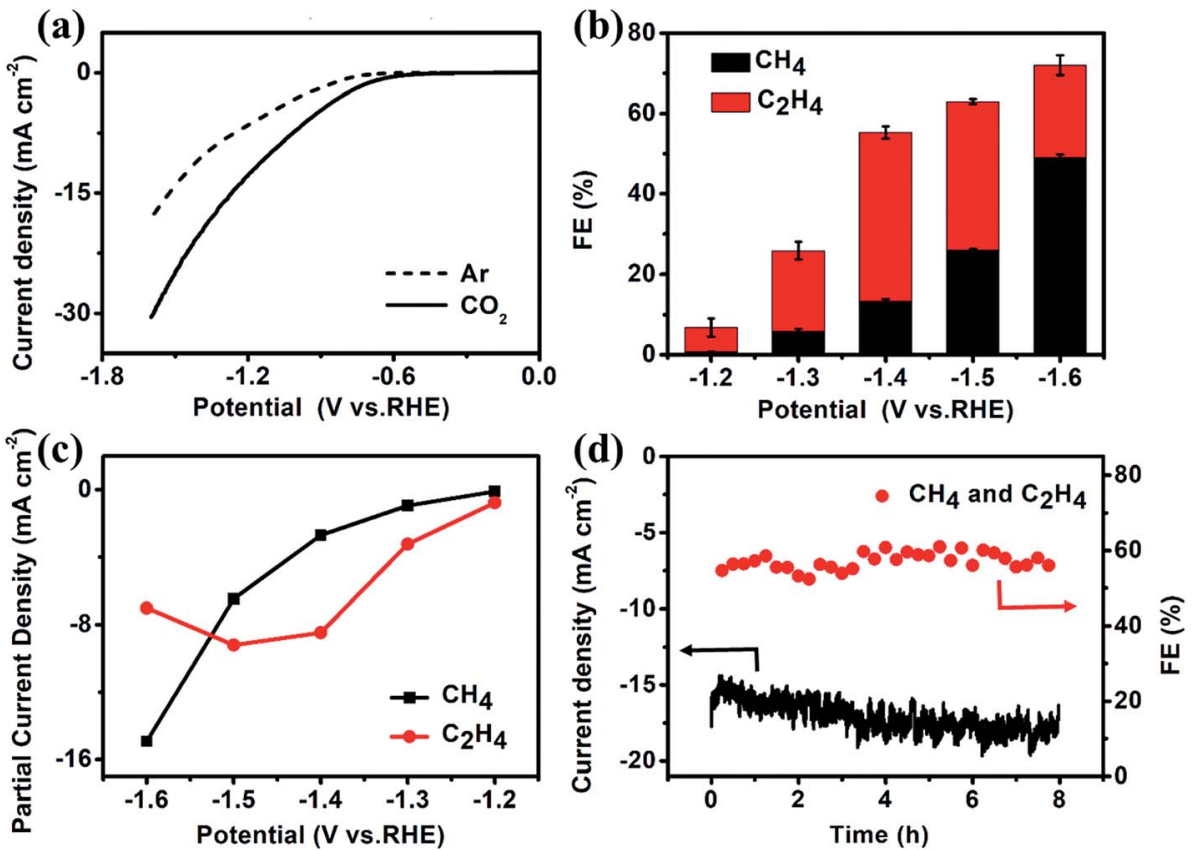

Fig. 2 (a) LSV curves, (b) the FE of $\mathrm{CH}_{4}$ and $\mathrm{C}_{2} \mathrm{H}_{4}$, (c) partial current density of $\mathrm{CH}_{4}$ and $\mathrm{C}_{2} \mathrm{H}_{4}$, and (d) $\mathrm{FE}$ and current density test at $-1.4 \mathrm{~V}$ vs. $\mathrm{RHE}$ for the s-Cu-ade MOF.

the $\mathrm{Cu}$-ade catalysts are used in Ar-saturated $0.1 \mathrm{M} \mathrm{KHCO}_{3}$ solution, only the $\mathrm{H}_{2}$ product is detected without any carboncontaining gaseous and liquid products such as $\mathrm{CO}$ and $\mathrm{CH}_{4}$. However in the $\mathrm{CO}_{2}$-saturated $0.1 \mathrm{M} \mathrm{KHCO}_{3}$ solution, the major hydrocarbon products including $\mathrm{CH}_{4}$ and $\mathrm{C}_{2} \mathrm{H}_{4}$ are detected by GC measurements and few liquid products such as $\mathrm{HCOOH}$ and $\mathrm{CH}_{3} \mathrm{CH}_{2} \mathrm{OH}$ are characterized by NMR analysis (Fig. S3 $\dagger$ ). These results suggest that $\mathrm{Cu}-\mathrm{MOFs}$ are effective for $\mathrm{CO}_{2}$ electrochemical reduction, whereas the reduction products are from $\mathrm{CO}_{2}$ rather than the carbon-containing $\mathrm{Cu}$-ade catalyst system.

The constant potential test method is used to investigate the $\mathrm{CO}_{2}$ reduction over three $\mathrm{Cu}$-ade MOF catalysts (Fig. S4 $\dagger$ ). The detailed analysis of $\mathrm{CO}_{2}$ electrochemical reduction shows that the main products of $\mathrm{CO}_{2}$ reduction are hydrocarbons and hydrogen (Fig. S5 $\dagger$ ). The faradaic efficiencies (FEs) of $\mathrm{CH}_{4}$ and $\mathrm{C}_{2} \mathrm{H}_{4}$ products over nanosheet structured $\mathrm{Cu}$-ade MOFs are shown in Fig. 2b. $\mathrm{C}_{2} \mathrm{H}_{4}$ is first produced at a more positive potential than $\mathrm{CH}_{4}$, which means that the electrochemical reduction of $\mathrm{CO}_{2}$ preferentially generates the $\mathrm{C}_{2} \mathrm{H}_{4}$ product at a lower potential. The total $\mathrm{FE}$ of hydrocarbons $\left(\mathrm{CH}_{4}\right.$ and $\left.\mathrm{C}_{2} \mathrm{H}_{4}\right)$ keeps increasing with more negative cathodic potentials and achieves the highest value of over $73 \%$ at a potential of $-1.6 \mathrm{~V}$ vs. RHE. Among them, the $\mathrm{FE}$ of $\mathrm{C}_{2} \mathrm{H}_{4}$ increases firstly and then decreases while the $\mathrm{FE}$ of $\mathrm{CH}_{4}$ keeps increasing along with the increasing cathodic potentials. The maximum $\mathrm{FE}$ of $\mathrm{C}_{2} \mathrm{H}_{4}$ can reach $45 \%$ at $-1.4 \mathrm{~V}$ vs. $\mathrm{RHE}$, and the maximum $\mathrm{FE}$ of $\mathrm{CH}_{4}$ is over $50 \%$ at $-1.6 \mathrm{~V}$ vs. RHE. This phenomenon is similar to other $\mathrm{Cu}$-based electrocatalysts for hydrocarbon production by $\mathrm{CO}_{2}$ electrolysis, as larger potentials induce more difficult $\mathrm{C}-\mathrm{C}$ coupling, thus resulting in decreased $\mathrm{C} 2$ products and increased C1 products. ${ }^{37-39}$ The partial current densities of $\mathrm{CH}_{4}$ and $\mathrm{C}_{2} \mathrm{H}_{4}$ at different potentials are shown in Fig. 2c. The partial current density of $\mathrm{C}_{2} \mathrm{H}_{4}$ is $9.2 \mathrm{~mA} \mathrm{~cm}^{-2}$ at $-1.5 \mathrm{~V} v s$. RHE, and the high current density is rare for MOF-derived catalysts for converting $\mathrm{CO}_{2}$ to $\mathrm{C}_{2} \mathrm{H}_{4} \cdot{ }^{23,25-27}$ At a potential of $-1.6 \mathrm{~V}$ vs. RHE, the partial current density of $\mathrm{C}_{2} \mathrm{H}_{4}$ is $15.0 \mathrm{~mA} \mathrm{~cm}^{-2}$ accompanied by a total $\mathrm{FE}$ of $73 \%$ for hydrocarbons $\left(\mathrm{CH}_{4}\right.$ and $\left.\mathrm{C}_{2} \mathrm{H}_{4}\right)$. Compared to the reported $\mathrm{Cu}$-complexes, these cathodized $\mathrm{Cu}$ MOFs show excellent efficiency for the electrochemical conversion of $\mathrm{CO}_{2}$ to $\mathrm{C}_{2}$ products (Table $\mathrm{S} 1 \dagger$ ).

The electrolysis stability of $\mathrm{Cu}$-ade MOF nanosheet catalysts is further investigated at $-1.4 \mathrm{~V}$ vs. RHE for 8 hours (Fig. 2d). The total $\mathrm{FE}$ of $\mathrm{CH}_{4}$ and $\mathrm{C}_{2} \mathrm{H}_{4}$ is stable at $\sim 60 \%$ during the whole stability test. However, the total current density increases slightly, which might be due to some side reactions, such as hydrogen evolution and the gradual reduction of $\mathrm{Cu}$-ade $\mathrm{MOF}$ nanosheets. The detailed FE evolution of $\mathrm{CH}_{4}$ and $\mathrm{C}_{2} \mathrm{H}_{4}$ is demonstrated in Fig. S7d. $\uparrow$ With prolonged electrolysis, the $\mathrm{FE}$ of the $\mathrm{C}_{2} \mathrm{H}_{4}$ product decreases and the $\mathrm{FE}$ of $\mathrm{CH}_{4}$ increases as time goes on. A similar trend is observed when electrolysis is performed at relatively negative electrode potentials; the FE of $\mathrm{C}_{2} \mathrm{H}_{4}$ decreases, and the $\mathrm{FE}$ of $\mathrm{CH}_{4}$ increases.

Among the three $\mathrm{Cu}$-ade MOFs, s-Cu-ade MOF nanosheets demonstrate the most significant partial current density and the highest $\mathrm{FE}$ for hydrocarbons. However, linear scan curves of $\mathrm{CO}_{2}$ reduction over the three $\mathrm{Cu}$-ade MOFs are similar (Fig. 3a). Very interestingly, the LSV curve of the s-Cu-ade in the Arsaturated electrolyte is in the middle, which implies that the hydrogen evolution side reaction over the s-Cu-ade MOF may be inhibited. The lower $\mathrm{FE}$ of $\mathrm{H}_{2}$ also indicates this phenomenon (Fig. S5 $\dagger$ ). The $\mathrm{FE}$ of both $\mathrm{CH}_{4}$ and $\mathrm{C}_{2} \mathrm{H}_{4}$ is more than $50 \%$ at $-1.4 \mathrm{~V}$ vs. RHE (Fig. 3b), and the partial hydrocarbon $\left(\mathrm{CH}_{4}\right.$ and 
(a)
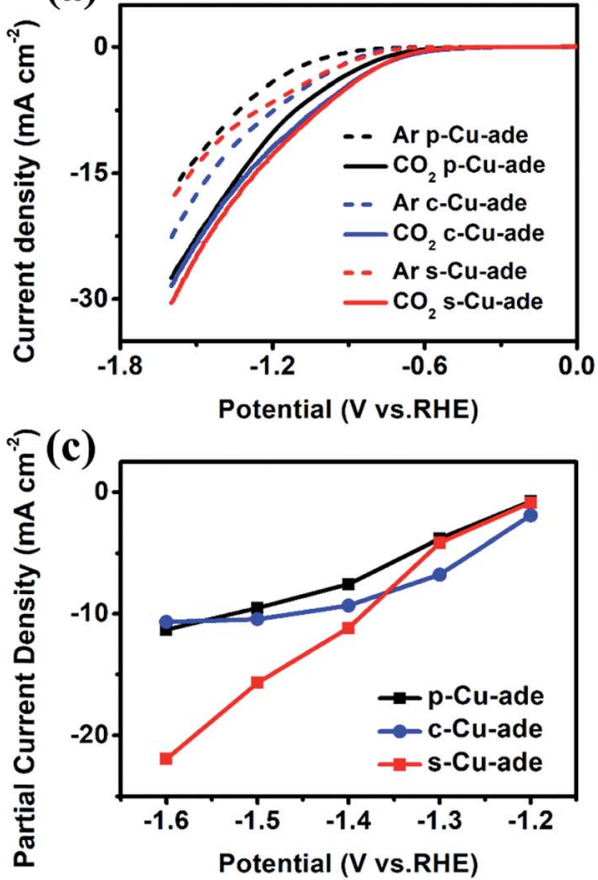

(b)

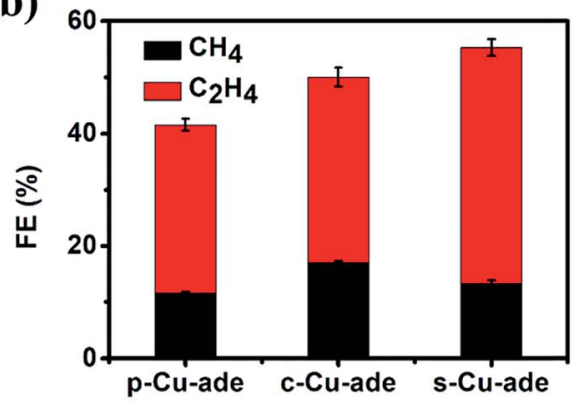

(d)

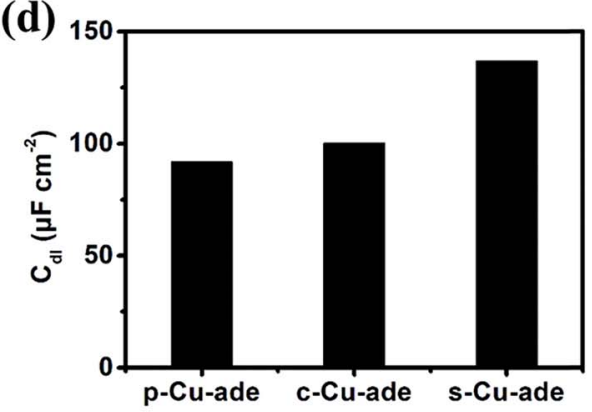

Fig. 3 (a) LSV curves, (b) $\mathrm{CH}_{4}$ and $\mathrm{C}_{2} \mathrm{H}_{4} \mathrm{FE}$ at -1.4 vs. $\mathrm{RHE}$, (c) partial current density of hydrocarbons $\left(\mathrm{CH}_{4}\right.$ and $\left.\mathrm{C}_{2} \mathrm{H}_{4}\right)$ and (d) $\mathrm{C}_{\mathrm{dl}}$ comparison of the three $\mathrm{Cu}$-ade MOFs.

$\mathrm{C}_{2} \mathrm{H}_{4}$ ) current density of s-Cu-ade is also higher at a relatively negative potential (Fig. 3c). The other two $\mathrm{Cu}$-ade materials show the same change rules in the $\mathrm{FE}$ of $\mathrm{CH}_{4}$ and $\mathrm{C}_{2} \mathrm{H}_{4}$. The $\mathrm{FE}$ of $\mathrm{C}_{2} \mathrm{H}_{4}$ first increases to $\sim 35 \%$ at $-1.4 \mathrm{~V} v s$. RHE and then declines, and the $\mathrm{FE}$ of $\mathrm{CH}_{4}$ always increases with the increased potentials (Fig. $\mathrm{S} 6$ and $\mathrm{S} 7 \dagger$ ). Among the three $\mathrm{Cu}$-ade MOFs, the performance of $\mathrm{CO}_{2}$ reduction to the hydrocarbons $\left(\mathrm{CH}_{4}\right.$ and $\mathrm{C}_{2} \mathrm{H}_{4}$ ) is dependent on the thickness of $\mathrm{Cu}$-ade MOFs, and the s$\mathrm{Cu}$-ade nanosheets demonstrate the best $\mathrm{CO}_{2}$ reduction performance (Fig. 3 and 55 ). Considering the same molecular structure and similar $\mathrm{CO}_{2}$ reduction behaviors in the activity and selectivity (Fig. S7 $\dagger$ ), the electrochemically active surface area (ECSA) and electrochemical impedance spectroscopy (EIS) measurements are further performed. To a certain extent, the ECSA represents the number of active sites determined by the electrochemical double layer capacitance (Fig. S8 $\dagger$ ). The capacitance is calculated by plotting current density differences against scan rates and the capacitance values of $\mathrm{p}$-Cu-ade, $\mathrm{c}$ $\mathrm{Cu}$-ade and s-Cu-ade are $\sim 92 \mu \mathrm{F} \mathrm{cm} \mathrm{cm}^{-2}, \sim 100 \mu \mathrm{F} \mathrm{cm}{ }^{-2}$ and $\sim 138 \mu \mathrm{F} \mathrm{cm}^{-2}$, respectively, (Fig. $3 \mathrm{~d}$ ) and the roughness factors $\left(R_{\mathrm{f}}\right)$ are 4.6, 5.0 and 6.9, respectively. Thus, ECSAs for p-Cu-ade, $\mathrm{c}-\mathrm{Cu}$-ade and $\mathrm{s}-\mathrm{Cu}$-ade are $0.9 \mathrm{~cm}^{2}, 0.98 \mathrm{~cm}^{2}$, and $1.34 \mathrm{~cm}^{2}$, respectively. The area-based activities of three samples demonstrate a similar trend in the $\mathrm{CO}_{2}$ reduction activity (Fig. S9†), indicating that the enhanced $\mathrm{CO}_{2}$ reduction activity of $\mathrm{Cu}$-ade MOF nanosheets is mainly ascribed to improved ECSAs, which provide more active sites that are exposed to the reactant.

Furthermore, the electrochemical impedance spectroscopy (EIS) measurement results and the equivalent circuit for the
Nyquist plots are displayed in Fig. S9b. $\uparrow$ The EIS data are fitted by the internal resistance $\left(R_{1}\right)$, the charge transfer resistance $\left(R_{\mathrm{S}}\right)$, and the constant phase elements (CPE 1 and 2). $\mathrm{Cu}$-ade MOF nanosheets exhibit the smallest transfer resistance $\left(R_{\mathrm{ct}}\right)$, which indicates fast charge transfer during the electrochemical reaction process. The thin structure could contribute to sufficient contact of the reactant on nanosheets, which will result in fast charge transfer over the $\mathrm{Cu}$-ade nanosheet catalyst to promote the hydrocarbon generation. Although the distribution of the reduction product mainly depends on the microstructure and intrinsic active $\mathrm{Cu}$-complex sites, obviously, the different morphology of $\mathrm{Cu}$-ade MOFs determines the activity of $\mathrm{CO}_{2}$ reduction. Moreover, the thinner nanosheets with more active sites exposed would lead to the enhanced activity for hydrocarbon generation.

The excellent performance in hydrocarbon generation attracts our attention to investigate the real active surface of $\mathrm{Cu}-$ ade MOFs. After the $\mathrm{CO}_{2}$ electrolysis, the morphology of $\mathrm{Cu}$-ade MOFs demonstrates significant changes (Fig. 4 and S10†). SEM observations show that the morphology of initial $\mathrm{Cu}$-ade MOF nanosheets is destroyed (Fig. 4a). Only the interconnected nanoparticles are present in the final cathodized MOFs. The corresponding TEM images of cathodized $\mathrm{Cu}$-ade MOFs after the $\mathrm{CO}_{2} \mathrm{RR}$ also indicate nanoparticle aggregation (Fig. $4 \mathrm{~b}$ inset). High-resolution (HR) TEM images show the inter-planar spacings of $\sim 0.18 \mathrm{~nm}$ and $0.21 \mathrm{~nm}$, which are related to the $\mathrm{Cu}(200)$ and $\mathrm{Cu}(111)$ facets, respectively (Fig. 4b). The XRD pattern of $\mathrm{Cu}$-ade MOFs after the electrolysis also demonstrates that the crystalline structure is completely changed (Fig. 4c), due to the missing peaks for $\mathrm{Cu}$-ade MOFs and the emergence 
(a)

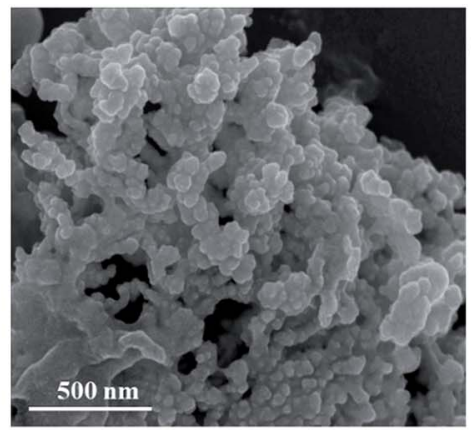

(d)

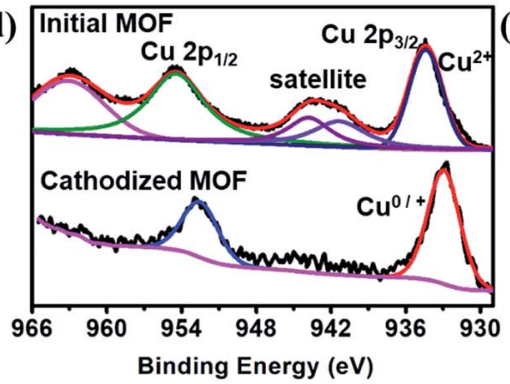

(b)

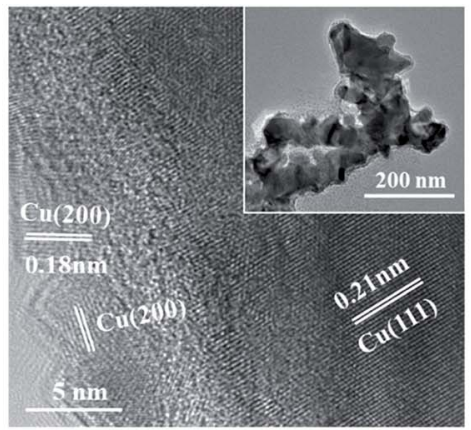

(c)

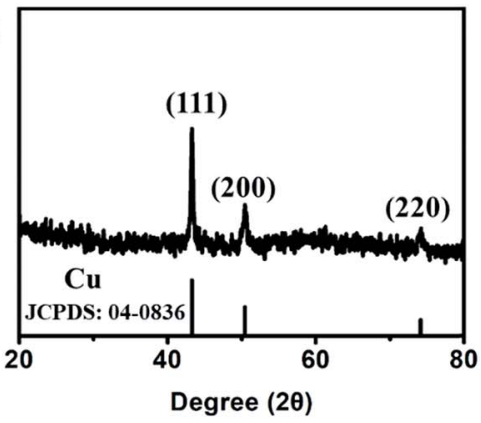

(e)

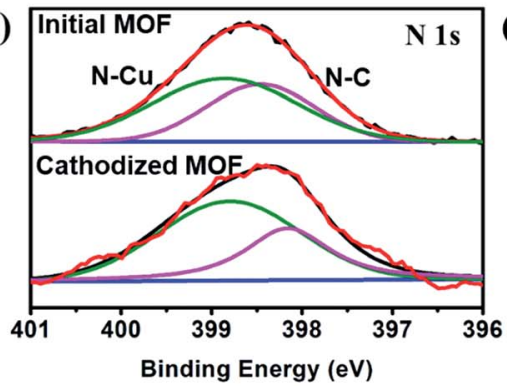

(f)

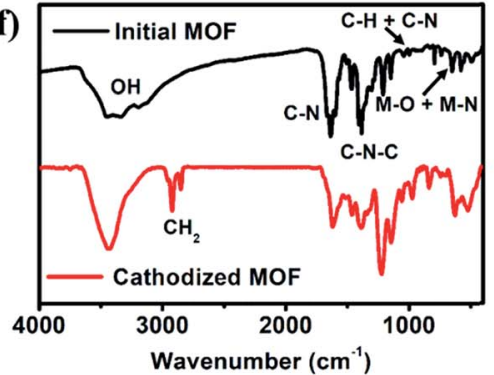

(g)

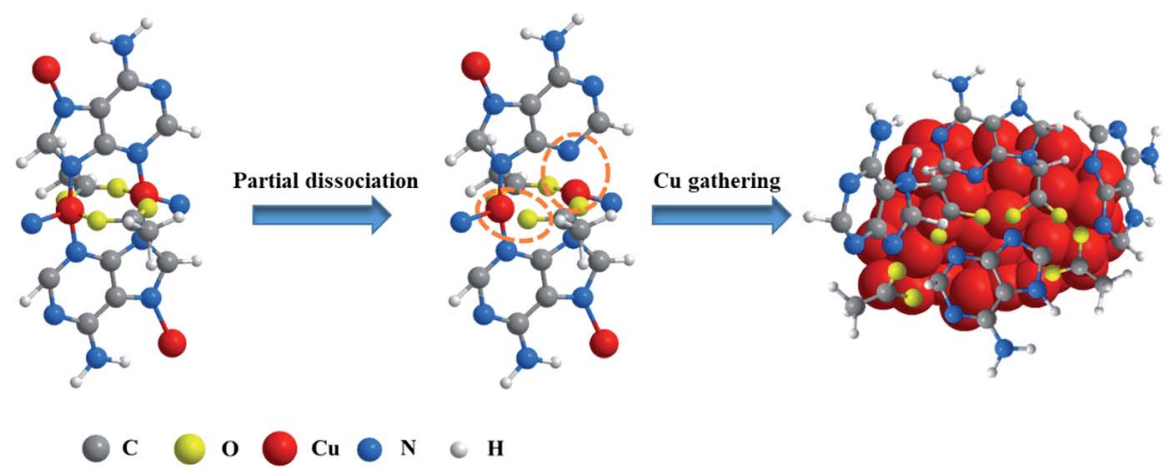

Fig. 4 (a) SEM image, (b) TEM image, and (c) XRD pattern of the cathodized s-Cu-ade MOF. (d) Cu 2p and (e) N 1s scan XPS patterns and (f) FT-IR spectra of the initial and cathodized $\mathrm{Cu}$-ade MOFs. (g) Proposed $\mathrm{Cu}$-ade MOF evolution.

of Cu crystals (JCPDS: 85-1326). The diffraction peaks located at $43.3^{\circ}, 50.4^{\circ}$ and $74.1^{\circ}$ are attributed to $\mathrm{Cu}(111), \mathrm{Cu}(200)$ and $\mathrm{Cu}(220)$, respectively (Fig. 4c), which is consistent with the electron microscopy observations (Fig. 4b). Obviously, metallic $\mathrm{Cu}$ nanoparticles are formed in situ by the reduction of $\mathrm{Cu}$-ade MOFs during the $\mathrm{CO}_{2}$ electroreduction process. The other two $\mathrm{Cu}$-ade MOFs also exhibit similar morphologies and structural evolution (Fig. S10†).

Elemental distribution indicates that the cathodized MOFs demonstrate two distinct element distributions, one is the copper enrichment region with $\mathrm{Cu}$ nanoparticles (Fig. S11a and $\mathrm{b} \dagger$ ), and another is the carbon enrichment region along with homogenous $\mathrm{Cu}$ element distribution (Fig. S11c and $\mathrm{d} \dagger$ ). For the $\mathrm{Cu}$-rich area, it can be inferred that the $\mathrm{Cu}$-ade coordination bond is broken from the $\mathrm{Cu}$-ade $\mathrm{MOF}$, and some $\mathrm{Cu}$ ion species are reduced to $\mathrm{Cu}$ clusters following the consequent segregation into copper nanoparticles. While for the C-rich area, it would be the organic ligands along with the residual $\mathrm{Cu}$ species. Nevertheless, the elemental mapping shows that other elements (C,
$\mathrm{O}$, and $\mathrm{N}$ ) are uniformly distributed on the area of the entire cathodized sample including the Cu-rich area (Fig. S12†). The surface of $\mathrm{Cu}$-ade MOFs is characterized using the XPS technique (Fig. S13 $\dagger$ ). The Cu 2p XPS spectra of initial $\mathrm{Cu}$-ade MOFs confirm the presence of $\mathrm{Cu}$ (II) species (Fig. 4d). After the cathodized $\mathrm{CO}_{2}$ electrolysis, the $\mathrm{Cu}(\mathrm{II})$ satellite peaks disappear (Fig. 4d), while the $\mathrm{Cu} 2 \mathrm{p}_{3 / 2}$ and $\mathrm{Cu} 2 \mathrm{p}_{1 / 2}$ belonging to $\mathrm{Cu}(0) /$ $\mathrm{Cu}(\mathrm{I})$ appear at 932.5 and $952.3 \mathrm{eV}$ (Fig. 4d). Further Cu LMM Auger peaks at $\sim 570.2 \mathrm{eV}$ and $\sim 567.7 \mathrm{eV}$ indicate the existence of $\mathrm{Cu}(\mathrm{I})$ and $\mathrm{Cu}(0)$ (Fig. S13 $\dagger$ ). Moreover, the $\mathrm{C} 1$ s and $\mathrm{O} 1 \mathrm{~s}$ XPS patterns of the initial and cathodized s-Cu-ade MOFs show that the ratio of the $\mathrm{C}-\mathrm{N}$ peak decreases and the $\mathrm{O}-\mathrm{Cu}$ peak disappears, which indicates the formation of metallic $\mathrm{Cu}$ in the cathodized $\mathrm{Cu}$-ade MOF nanosheets. The coordination environment of $\mathrm{N}$ species was analyzed using the XPS results (Fig. 4e). In the initial Cu-MOFs, $\mathrm{N}$ binds with $\mathrm{C}$ and $\mathrm{Cu}$ to form stable MOFs (Fig. 4e). After the electrolysis, the $\mathrm{N}-\mathrm{C}$ binding demonstrates a slight decrease, while the $\mathrm{N}-\mathrm{Cu}$ binding increases accordingly (Fig. 4e). This transformation suggests 
the splitting of $\mathrm{N}-\mathrm{C}$ ligands and the enhancement of $\mathrm{N}$-containing ligands on the resultant $\mathrm{Cu}$ nanocrystals, which agrees well with the similar structural evolution in the microscopy observation (Fig. S12 $\dagger$ ). Moreover, the Fourier-transform infrared spectroscopy (FTIR) pattern also indicates the MOF structure evolution and the residual $\mathrm{N}-\mathrm{Cu}$ and $\mathrm{N}-\mathrm{C}$ bonds (Fig. 4f). ${ }^{31}$ The peak at $\sim 2900 \mathrm{~cm}^{-1}$ is related to $\mathrm{H}-\mathrm{C}-\mathrm{H}$, and the enhanced peak at $\sim 550 \mathrm{~cm}^{-1}$ suggests the partial broken $\mathrm{N}-\mathrm{C}$ and formed $\mathrm{N}-\mathrm{C}$ in the cathodized $\mathrm{Cu}$-ade MOF. Besides, the $\mathrm{CuO}$ nanosheet derived from s-Cu-ade is used to catalyze $\mathrm{CO}_{2}$ reduction. As observed from the SEM and XRD results (Fig. S14 $\dagger$ ), the surface of inorganic $\mathrm{CuO}$ becomes rough after annealing Cu-MOFs. The primary product of $\mathrm{CO}_{2}$ reduction is $\mathrm{CH}_{4}$ at a relatively negative potential. The maximum $\mathrm{FE}$ of $\mathrm{CH}_{4}$ reaches $32 \%$ at $-1.6 \mathrm{~V}$ vs. RHE. Therefore, this result, to a certain extent, proves that the as-formed $\mathrm{Cu}$ functionalized by the nitrogen containing organic ligands in the cathodized $\mathrm{Cu}$ MOFs is essential for converting $\mathrm{CO}_{2}$ toward hydrocarbon generation.

$\mathrm{CH}_{4}$ and $\mathrm{C}_{2} \mathrm{H}_{4}$ are the major products of cathodized $\mathrm{Cu}-\mathrm{MOF}$ catalyzed $\mathrm{CO}_{2}$ reduction. In the cathodized MOFs, the derived $\mathrm{Cu}$ nanoparticles demonstrate the formation of $\mathrm{Cu}$ clusters with abundant (111) and (100) facets. The low-index $\mathrm{Cu}(100)$ plane favors the production of $\mathrm{C}_{2} \mathrm{H}_{4}$ while the $\mathrm{Cu}(111)$ facets are mainly responsible for the $\mathrm{CH}_{4}$ yield. ${ }^{40}$ Moreover, from the full potential $\mathrm{FE}$ of $\mathrm{C}_{2} \mathrm{H}_{4}$ and $\mathrm{CH}_{4}$ (Fig. 2b) and the stability test (Fig. S7 $\dagger+$ ), the $\mathrm{FE}$ of $\mathrm{C}_{2} \mathrm{H}_{4}$ product decreases and the $\mathrm{FE}$ of $\mathrm{CH}_{4}$ increases with enhancing the potential or prolonging the electrolysis time. It is evident that the formation of $\mathrm{CH}_{4}$ and $\mathrm{C}_{2} \mathrm{H}_{4}$ is competitive in the reaction kinetics to some extent, the pathway of $\mathrm{C}_{2} \mathrm{H}_{4}$ would be inhibited, and then the generation of $\mathrm{CH}_{4}$ could be promoted along with the increased potential or electrolysis time. The $\mathrm{CO}^{*}$ dimerization pathway is sluggish, yet this can't be omitted from the reaction pathway for $\mathrm{C} 2\left(\mathrm{C}_{2} \mathrm{H}_{4}\right)$ species under highly negative potentials, ${ }^{\mathbf{4 1}}$ consequently, the reaction for $\mathrm{CH}_{4}$ and $\mathrm{C}_{2} \mathrm{H}_{4}$ products undergo the hydrogenation and dimerization of the intermediate $\left(\mathrm{COH}^{*}\right.$ or $\left.\mathrm{CHO}^{*}\right){ }^{41}$ After the formation of the $\mathrm{CO}^{*}$ intermediate, the $\mathrm{COH}^{*}$ or $\mathrm{CHO}^{*}$ is the next critical intermediate for further hydrogenation to form $\mathrm{CH}_{4}$ or dimerization to produce $\mathrm{C} 2$ species on $\mathrm{Cu}(111)$ and $\mathrm{Cu}(100) .{ }^{42,43}$ Compared to the formation of $\mathrm{C}_{2} \mathrm{H}_{4}$ by the dimerization process with a higher barrier, the intermediates $\left(\mathrm{COH}^{*}\right.$ and $\left.\mathrm{CHO}^{*}\right)$ prefer to couple with protons and undergo hydrogenation to form $\mathrm{CH}_{4}$. Furthermore, the $\mathrm{N}$ 1s XPS spectra show the decreased $\mathrm{N}-\mathrm{C}$ proportion and enhanced $\mathrm{N}-\mathrm{Cu}$ in the cathodized Cu-MOFs (Fig. 4 and S13 $\dagger$ ). The presence of N-containing groups would activate the protons and stabilize the intermediates $\mathrm{CO}^{*} / \mathrm{CHO}^{*}$ of $\mathrm{CO}_{2}$ reduction to promote further hydrogenation to form hydrocarbons. ${ }^{32}$ Therefore, the higher ratio of $\mathrm{N}-\mathrm{Cu}$ in the cathodized $\mathrm{Cu}-\mathrm{MOF}$ would probably determine the efficient electrochemical reduction of $\mathrm{CO}_{2}$ towards hydrocarbons. Based on the experimental observation and analysis results, the $\mathrm{CO}_{2}$ reduction process over the cathodized $\mathrm{Cu}-\mathrm{MOF}$ sould be proposed. Under the reductive environment, the bond between $\mathrm{Cu}$ and ade ligands could be broken and the organic N-containing ligands mostly cover the formed $\mathrm{Cu}$ nanoparticles. Benefitting from the presence of $\mathrm{N}-$
$\mathrm{Cu}$, the hydrogenation and dimerization of $\mathrm{CHO}^{*} / \mathrm{COH}^{*}$ could more easily occur to form hydrocarbons.

In summary, cathodized $\mathrm{Cu}$-ade-MOFs have been investigated for efficient electrochemical $\mathrm{CO}_{2}$ reduction towards hydrocarbon generation. The cathodized $\mathrm{Cu}^{\mathrm{II}}$ /ade-MOF nanosheets demonstrate excellent catalytic conversion towards hydrocarbon production with a total hydrocarbon faradaic efficiency (FE) of over $73 \%$. Primarily, ethylene $\left(\mathrm{C}_{2} \mathrm{H}_{4}\right)$ is mainly produced at $-1.4 \mathrm{~V}$ vs. RHE with a maximum $\mathrm{FE}$ of $45 \%$ and a partial current density of $8.5 \mathrm{~mA} \mathrm{~cm}{ }^{-2}$, while methane $\left(\mathrm{CH}_{4}\right)$ is mainly produced at $-1.6 \mathrm{~V} v s$. RHE with a FE of $50 \%$ and partial current density of $\sim 15 \mathrm{~mA} \mathrm{~cm}{ }^{-2}$. It is found that $\mathrm{Cu}$-ade MOFs exhibit in situ structural evolution under the reductive $\mathrm{CO}_{2}$ environment. The reconstruction of cathodized $\mathrm{Cu}^{\mathrm{II}} /$ ade-MOFs and the formed $\mathrm{Cu}$ nanoparticles functionalized by the nitrogen containing ligands would contribute to the excellent $\mathrm{CO}_{2}$ conversion performance. This work would provide valuable insights and opportunities for the rational design of $\mathrm{Cu}$-based MOF catalysts for highly efficient conversion of $\mathrm{CO}_{2}$ towards hydrocarbon generation.

\section{Conflicts of interest}

There are no conflicts to declare.

\section{Acknowledgements}

This work is funded by the National Natural Science Foundation of China (21802048, 21805103, 21805104), the Fundamental Research Funds for the Central Universities (2018KFYXKJC044, 2018KFYYXJJ121, 2017KFXKJC002) and the National 1000 Young Talents Program of China. The authors also acknowledge the support of the Analytical and Testing Center of Huazhong University of Science and Technology for XRD, XPS, NMR, SEM, and TEM measurements.

\section{References}

1 N. Abas and N. Khan, J. CO ${ }_{2}$ Util., 2014, 8, 39.

2 S. Kagawa, S. Suh, K. Hubacek, T. Wiedmann, K. Nansai and J. Minx, Glob. Environ. Change, 2015, 35, 486.

3 K. Li, B. Peng and T. Peng, ACS Catal., 2016, 6, 7485.

4 M. Liu, Y. Pang, B. Zhang, P. De Luna, O. Voznyy, J. Xu, X. Zheng, C. T. Dinh, F. Fan, C. Cao, F. P. G. de Arquer, T. S. Safaei, A. Mepham, A. Klinkova, E. Kumacheva, T. Filleter, D. Sinton, S. O. Kelley and E. H. Sargent, Nature, 2016, 537, 382.

5 G. Centi, E. A. Quadrelli and S. Perathoner, Energy Environ. Sci., 2013, 6, 1711.

6 L. Zhang, Z.-J. Zhao and J. Gong, Angew. Chem., Int. Ed., 2017, 56, 11326.

7 C. S. Diercks, Y. Liu, K. E. Cordova and O. M. Yaghi, Nat. Mater., 2018, 1.

8 Q. Li, J. Fu, W. Zhu, Z. Chen, B. Shen, L. Wu, Z. Xi, T. Wang, G. Lu, J. j. Zhu and S. Sun, J. Am. Chem. Soc., 2017, 139, 4290.

9 J. Pan, Y. Sun, P. Deng, F. Yang, S. Chen, Q. Zhou, H. S. Park, H. Liu and B. Yu Xia, Appl. Catal., B, 2019, 255, 117736. 
10 S. Liu, J. Xiao, X. F. Lu, J. Wang, X. Wang and X. W. Lou, Angew. Chem., Int. Ed., 2019, 58, 8499.

11 Y. Wang, J. Chen, G. Wang, Y. Li and Z. Wen, Angew. Chem., Int. Ed., 2018, 130, 13304.

12 K. Tran and Z. W. Ulissi, Nat. Catal., 2018, 1, 696.

13 J. Qiao, Y. Liu, F. Hong and J. Zhang, Chem. Soc. Rev., 2014, 43, 631.

14 H. Xie, T. Wang, J. Liang, Q. Li and S. Sun, Nano Today, 2018, 21, 41.

15 Z. Gu, H. Shen, L. Shang, X. Lv, L. Qian and G. Zheng, Small Methods, 2018, 2, 1800121.

16 A. Vasileff, C. Xu, Y. Jiao, Y. Zheng and S.-Z. Qiao, Chem, 2018, 4, 1809.

17 W. Tang, A. A. Peterson, A. S. Varela, Z. P. Jovanov, L. Bech, W. J. Durand, S. Dahl, J. K. Nørskov and I. Chorkendorff, Phys. Chem. Chem. Phys., 2012, 14, 76.

18 R. Reske, H. Mistry, F. Behafarid, B. Roldan Cuenya and P. Strasser, J. Am. Chem. Soc., 2014, 136, 6978.

19 R. Kas, R. Kortlever, A. Milbrat, M. T. M. Koper, G. Mul and J. Baltrusaitis, Phys. Chem. Chem. Phys., 2014, 16, 12194.

20 D. Ren, Y. Deng, A. D. Handoko, C. S. Chen, S. Malkhandi and B. S. Yeo, ACS Catal., 2015, 5, 2814.

21 Y. Yan, T. He, B. Zhao, K. Qi, H. Liu and B. Y. Xia, J. Mater. Chem. A, 2018, 6, 15905.

22 R. Hinogami, S. Yotsuhashi, M. Deguchi, Y. Zenitani, H. Hashiba and Y. J. E. E. L. Yamada, ECS Electrochem. Lett., 2012, 1, H17.

23 Z. Weng, J. Jiang, Y. Wu, Z. Wu, X. Guo, K. L. Materna, W. Liu, V. S. Batista, G. W. Brudvig and H. Wang, J. Am. Chem. Soc., 2016, 138, 8076.

24 S. Lin, C. S. Diercks, Y.-B. Zhang, N. Kornienko, E. M. Nichols, Y. Zhao, A. R. Paris, D. Kim, P. Yang, O. M. Yaghi and C. J. Chang, Science, 2015, 349, 1208.

25 Z. Weng, Y. Wu, M. Wang, J. Jiang, K. Yang, S. Huo, X.-F. Wang, Q. Ma, G. W. Brudvig, V. S. Batista, Y. Liang, Z. Feng and H. Wang, Nat. Commun., 2018, 9, 415.
26 J.-X. Wu, S.-Z. Hou, X.-D. Zhang, M. Xu, H.-F. Yang, P.-S. Cao and Z.-Y. Gu, Chem. Sci., 2019, 10, 2199.

27 J. Albo, D. Vallejo, G. Beobide, O. Castillo, P. Castaño and A. Irabien, ChemSusChem, 2017, 10, 1100.

28 L. Su, X. Cui, T. He, L. Zeng, H. Tian, Y. Song, K. Qi and B. Y. Xia, Chem. Sci., 2019, 10, 2019.

29 S. Pérez-Yáñez, G. Beobide, O. Castillo, J. Cepeda, A. Luque, A. T. Aguayo and P. Román, Inorg. Chem., 2011, 50, 5330.

30 S. Pérez-Yáñez, G. Beobide, O. Castillo, M. Fischer, F. Hoffmann, M. Fröba, J. Cepeda and A. Luque, Eur. J. Inorg. Chem., 2012, 2012, 5921.

31 S. Pérez-Yáñez, G. Beobide, O. Castillo, J. Cepeda, A. Luque and P. Román, Cryst. Growth Des., 2012, 12, 3324.

32 M. S. Xie, B. Y. Xia, Y. Li, Y. Yan, Y. Yang, Q. Sun, S. H. Chan, A. Fisher and X. Wang, Energy Environ. Sci., 2016, 9, 1687. 33 Y. Fang and J. C. Flake, J. Am. Chem. Soc., 2017, 139, 3399. 34 S. Ahn, K. Klyukin, R. J. Wakeham, J. A. Rudd, A. R. Lewis, S. Alexander, F. Carla, V. Alexandrov and E. Andreoli, ACS Catal., 2018, 8, 4132.

35 Y. Qiu, H. Zhong, W. Xu, T. Zhang, X. Li and H. Zhang, J. Mater. Chem. A, 2019, 7, 5453.

36 I. Burneo, K. C. Stylianou, S. Rodriguez-Hermida, J. Juanhuix, X. Fontrodona, I. Imaz and D. Maspoch, Cryst. Growth Des., 2015, 15, 3182.

37 K. P. Kuhl, E. R. Cave, D. N. Abram and T. F. Jaramillo, Energy Environ. Sci., 2012, 5, 7050.

38 D. Ren, J. Fong and B. S. Yeo, Nat. Commun., 2018, 9, 925.

39 K. Jiang, R. B. Sandberg, A. J. Akey, X. Liu, D. C. Bell, J. K. Nørskov, K. Chan and H. Wang, Nat. Catal., 2018, 1, 111. 40 Y. Hori, I. Takahashi, O. Koga and N. Hoshi, J. Mol. Catal. A: Chem., 2003, 199, 39.

41 W. Luo, X. Nie, M. J. Janik and A. Asthagiri, ACS Catal., 2015, 6, 219.

42 F. Calle-Vallejo and M. T. Koper, Angew. Chem., Int. Ed., 2013, 52, 7282 .

43 J. H. Montoya, C. Shi, K. Chan and J. K. Nørskov, J. Phys. Chem. Lett., 2015, 6, 2032. 